\title{
The Problems of and Solutions to Micro-teaching for English Pedagogical Students
}

\author{
Liu Yang \\ Huanghe Science and Technology College \\ Zhengzhou, Henan, China
}

\begin{abstract}
Microteaching, also known as "micro teaching", "small-scale teaching", is a teaching method by applying modern teaching technologies to the training of normal students as well as in-service teachers' teaching skills. In the current background of information technology, microteaching goals, teaching process and teaching models are given new conceptions and characteristics. Inevitably, English normal students in microteaching have encountered a series of problems, therefore, discussing the problems and countermeasures of microteaching has great theoretical significance and practical value. This paper starts from a successive of problems in Micro-teaching for English Pedagogical Students and puts forward some corresponding countermeasures, in order to better play the role of microteaching in training English normal students' teaching skills.
\end{abstract}

Keywords-microteaching; English pedagogical students; English teaching skills

\section{INTRODUCTION}

Microteaching, also known as "micro teaching", "smallscale teaching", is a teaching method using modern teaching technology to the training teaching skills of normal students as well as in-service teachers. Meanwhile, it is a purposeful and practical system of control, making the students in normal universities and teachers focus on solving a specific teaching behavior, or in the controlled conditions to learn.

Owing to its practical functions and solid theoretical foundation, microteaching plays a great role in student teachers and in-service teachers' skill training. However, unavoidably, some problems have gradually appeared in the implementation of microteaching whether for objective or subjective factors, hindering it from better playing its own function. Given to this problem, so far a number of people have proceeded relative study of microteaching, for example, experts in abroad have found many disadvantages of the poor preparation of the prospective teachers in the area of procedural knowledge, like dealing with unmotivated students and classroom management. They emphasized teachers' role and the learning of general education skills. Meanwhile, scholars in our country also analyzed some issues of microteaching, including the lack of knowledge about microteaching, insufficient class hours and equipment, unreasonable evaluation and so on. But in spite of the growing research on microteaching, there is little attention paid on the English pedagogical students' using of microteaching and some problems still need to be further inquired. What's more, in the current information and technological education, the move to improve the quality of education, along with the educational and microteaching goals, skills training, training modes and other aspects have been given new significance and characteristics. Therefore, deeply analyzing the problems of microteaching and putting forward countermeasures have certain theoretical and practical value.

\section{ENGLISH MICROTEACHING}

\section{A. Definition}

The word Microteaching first appeared in Stanford University in 1963. The teachers in this school challenged the traditional teaching methods, teaching by using electronic devices, then gradually forming microteaching. Followed by the educational reforms, microteaching had been increasingly adopted by the education sectors. Microteaching includes: determining the training capacity with prior studies, demonstration, micro teaching practice, observation, feedback and evaluation, micro teaching strategy design and so on. The initiator, professor D. Allen and his companion, Eve define it as a controlled practical system of teaching skill training, which allows normal students and in-service teachers to focus on solving a specific teaching behavior, or study in controlled conditions, and which is built on the basis of educational theory and audio-visual technology.

According to the definition of microteaching defined by Allen and other researchers, meanwhile, combining it with English teaching, a definition of English microteaching can be drawn to a conclusion that it is a purposeful and practical system of control for those who are or want to be English teacher to be possibly focused to solve a specific teaching behavior. With the guidance of modern education theories, the assist of educational technology, such as audios, videos, and the teaching exercise in the laboratory room, microteaching selectively emulates the knowledge and skills needed to be grasped to make the various kinds of normal university students and in-service teachers' teaching acts observed, described and evaluated. 


\section{B. Characteristics}

As a newly type method for training teachers' skills, microteaching has many traits in common with traditional teaching. For instance, they all lay emphasis on the decomposition of the teaching process, the scientific training planning for a single teaching skill. Students are usually divided into several groups to proceed training, and after that, there will be the feedback and assessments. Except these, microteaching also possesses plenty of other features and edges that traditional teaching can not be paralleled to, which can be concluded into one sentence, "the micromation of training topics, the standardized skills and actions, the using of audio and video in the process of recording, the timeliness of emulating and evaluation." To put it in concrete, it has the following features: (1) The connection between theories and practice. (2) The micromation of the teaching process. (3) The controllability of objectives. (4) Small scale and short time. (5) The timely feedback. (6) The use of audio and video in the process

\section{Procedures}

Only knowing the complete English microteaching procedures clearly, can we better give full play of its functions and improve English normal students' teaching capabilities. It's undoubted that owing to the flexibility of teaching, different English teachers will unconsciously form diverse teaching procedures, but generally speaking, they are based on a certain teaching process. The suggested English microteaching procedures are the following steps: (1) checking the assignments assigned last class. (2) introducing the teaching content through presentation, inquiring or question discussion. (3) the teacher explains the training form, method and steps. (4) the student prepares lesson and practices it respectively. (5) students have drill in group manner. (6) students are distributed into groups to have microteaching in micro room or laboratory. (7) watching the teaching video and evaluating it from the teacher and students. (8) giving marks and feedback according to the video and recording the results. (9) assigning the training assignments.

\section{THE PROBLEMS OF ENGLISH MicROTEACHING}

\section{A. The Lack of Theoretical Knowledge of Microteaching}

The learning of microteaching theories is a guarantee for its well-operation. Only on the premises of knowing the basic principles, training steps and contents, English normal students are able to utilize the teaching facility to further improve their professional capabilities. But it's not a rare phenomenon that lacking in-depth understanding of microteaching is reflected both in English teachers and students.

Firstly, students are not introduced some theoretical knowledge of microteaching but solely receiving the skill training. The omitted introduction for microteaching theories leads students' misunderstanding that they consider it's useless to acquire this knowledge. At the end of this lesson, English normal students are just familiar with the surrounding of microteaching, but ignorant about its concept, origin, development, characteristics and theoretical foundation. Secondly, some instructors neither have paid enough attention to introduce students the theory of microteaching, nor have constructed their own knowledge structure of microteaching. Thus, they can't truly play the role to professionally build bridges or assume subsidiary between students and practical exercise. Thirdly, there are many normal universities still not regarding microteaching course as normal students' compulsory education curriculum yet, and the nature of this scientific knowledge is not formed uniform agreement.

\section{B. The Inappropriate Class Designing}

To begin with, the improper distribution of theoretical explanation and practical operation. In English microteaching, teachers or students sometimes can not balance the theory and practice. On the one hand, English teachers hold the view that it's highly important to make students understand the behind theory of each teaching skill, so that students can transfer the learned skills into any teaching situation. Thus, in their class, the theoretical explanation takes up a large proportion, while students' practical performance is finished in a short time. On the other hand, some teachers consider the actual operation of English teaching skill is more important than the theoretical introduction. In this circumstance, the theoretical part tends to be introduced by a couple of words, while most of class time is left to practical training.

Secondly, the inapt arrangement of English microteaching process. As we all know, there are some special teaching procedures in English microteaching. Though it has certain similarities to traditional teaching, the plenty of differences are more obvious. If not paid much attention, it will bring negative influence on students' learning effect. For instance, some English teachers have formed a set of their own teaching habits and they have been used to it before teaching in microteaching room, then in a sudden, they are not accustomed to English microteaching.

Thirdly, the dissatisfied implementation way of teaching activity. English microteaching often involves in a series of interesting and meaningful activities, but some instructors are not excel in making use of their existing teaching resources and unable to activate students' initiative. For example, students are not divided into several groups but in a whole class to finish a task, after that, the teacher selects one or two students to have a show and then make comments. In this process, only few students have the practical exercise, while most students are ignored. And there is only the teacher evaluation in the class, without peer assessment, consequently, students may lose the initiative and interest in it. Besides, it's better to implement the English microteaching in several groups, for students can communicate with and give a hand to each other.

\section{The Isolation of Individual Skill from Integrated Skills}

What are the microteaching goals? This is the first problem we need to be clear in the construction and development of microteaching course. Allen believes that teaching skills are highly migratory, and the sub-skills 
formed in microteaching can be migrated to any other teaching situation, so as to the training of the sub-skills is the main objective in microteaching training. This "sub-skill model" is simple and easy to operate. However, although it can be effective in changing the teaching behavior of teachers in a short time, it ignores the survival soil of teaching skills-real classroom culture, which triggers people's doubts: whether the teaching ability of teachers can be completely decomposed? Can teaching skills formed by abandoning some related factors really meet the needs of the teaching practice?

In the specific implementation of this model, there may be two kinds of results. First, the individual English teaching skill is given sufficient attention, but it is failed to be applied into real English teaching context. Meanwhile, because of the neglect of comprehensive teaching objectives, the training of other skills are tended to be overlooked. For instance, some students diligently practice a task assigned by a teacher after class, such as drawing stick figure on the blackboard. In the next class, their focus is on performing this single skill well. In general cases, they perform this individual skill very well, but seen in an integrated teaching process, the performance of other skills are not good even terrible. The reason for this is that they only focus on the individual skill training, without taking into account and coordinating with other skills. Besides, owing to the short time of microteaching class, and lack of some necessary and timely practice, English normal students can not fully absorb and transform the newly learned knowledge into their existing knowledge structure, let alone the flexible application of them in real teaching context. As a result, the individual skill can not be transferred into other teaching situation.

In another case, English normal students consider practical microteaching involves in many aspects of teaching, such as lectures, methods, stage manners and so on. They feel that these play an important role in the English teaching. As long as the overall performance is excellent, there is no need to be too concerned about the individual skill training, so they do not want to learn too much about the theory of individual skill, resulting in a "sharp-tongued, thick-skinned and belly empty" illusion. We believe that both views are one-sided and it is preferable to combine the two, for only to grasp the degree, will we have a qualitative leap.

\section{The Unscientific Evaluation Mechanism}

Evaluation or assessment is the basic method and process of control, whose purpose is to make the controller know the result of past activities or processes, and to adjust the next activity, to achieve the purpose. It is a critical and core junction in English microteaching class, concerned with the success or failure of this class in a large degree.

The unscientific evaluation system mainly reflects on the following aspects. Firstly, the students' evaluation on microteaching after class is almost a mere formality. For example, the instructor will distribute students the evaluation criteria of English teaching skills beforehand of each class. Students will take this matter seriously for the first few times, and give scores strictly according to the requirements of each teaching skill standard, but won't value it after a section of time, and sometimes close to class, they will casually write some points in the scoring column. For the limited time left for evaluation, students can not give objective assessment nor constructive suggestions. Day by day, if no teacher correction, the evaluation is degraded to a mere formality. Secondly, the evaluation of English microteaching skills lacks of scientific standards. For instance, sometimes it's time for mentors to evaluate students' classroom performance. Nevertheless, they can not accurately recall and describe some of the details, but depend on experience and impressions to evaluate. Their evaluation tends to be very general with a strong subjectivity. Another case is that the teacher shows a student's classroom teaching video, and then asks students' views on it. Influenced by the factors, such as, valuing face, interrelationships and so on, students or teachers are possibly unwilling to express their true thoughts about it, but give false comments or compliments. Hence, it causes the deviation between evaluation and factual performance. Thirdly, the highlighted evaluation with ignored corrective measures. Teachers sometimes mechanically choose a fixed time for students to evaluate and give their opinions. But as for how student should do to correct and how to detect if there is no mistake, they have not been paid much attention. Finally, the trainee have not played their role very well, for our evaluation is generally concentrated on the lecturer, instead the trainee. These all do not concord the requirements of evaluation, impeding it from improving trainee's English teaching skills.

\section{E. The Insufficiency of Class Hours and Equipment}

The amount of microteaching class hours in our country is far below that in abroad. Microteaching course, such as in Australia, University of Sydney and New South Wales, is opened 4 hours per week, 13 weeks, a total of 52 hours. In UK, microteaching arrangements are within the four-year Bachelor of Education courses, and the completion of courses needs 42 weeks, 5 hours per week, totaling 210 hours. At present, many normal universities usually open up micro class for only 7-8 weeks, two hours per week a total of 14-16 hours, or even less than that. In addition, the normal professional curriculum of microteaching is generally arranged at a very late time, such as in junior or senior, when students have a high need for the classes training, but are impeded by the limited class hour. Combined with a relatively small number of micro classrooms, each student's training time only lasts for 4 to 5 times. The time is too limited for students to bring everything into play, so the effectiveness of the teaching may be weaken a lot.[10] In addition, as is known to all that microteaching needs a certain hardware facilities, nevertheless, although many of our colleges and universities have established normal microteaching laboratory, because of the undue attention paid on microteaching, the lack of funds or the restriction of some other objective factors, the insufficiency of equipment is still a tricky problem in many normal colleges. One can imagine that the poor condition will have a negative impact on the students' English teaching skills training. 


\section{The SOLUTIONS TO ENGLISH MicROTEACHING}

\section{A. Enriching the Theoretical Knowledge of Microteaching}

To correctly use the teaching skills, it is a prerequisite to study the teaching skills. In other words, grasping the basic theory is the fundamental basis to carry out microteaching. Once theoretical knowledge of basic skills is absorbed by students, they can eliminate misunderstandings and increase the awareness of microteaching. It includes two things:

First, in-depth studying of microteaching disciplinary nature. Microteaching should be regarded as teachers' educational compulsory course. In the form of compulsory courses, English pedagogical students and teachers will pay much attention on it and try to learn it deeply. Second, deeply researching the classification of skills of microteaching. In addition to learning the nature of the subject, it is more important to master the classification and learning method of each skill. The theoretical content of English microteaching training is mainly composed by leading-in skill, questioning skill, blackboard designing skill, presentation skill as well as the characteristics, functions, performing method of each skill. Teachers ought to strengthen normal students' awareness of English microteaching, increasing learners' theoretical storage of it, aiding them to put theory into practice to make normal students achieve the best microteaching training effect.

In addition, before having English micrteaching, normal students are supposed to earnestly conclude and consolidate the knowledge about linguistic teaching theory and practice, being familiar with the teaching method that English microteaching will possibly use. Meanwhile, students ought to systematically learn some classroom expressions of English, watching more superior English teaching video, from which they can learn how to organize class teaching successfully. Furthermore, they need to summarize some basic language teaching theories, such as foreign language teaching principle, the principle and method of classroom management, learner difference and the fostering method of their interest and motivation.

\section{B. Optimizing the Class Designing}

According to the issues concerned with class designing of English micoteaching mentioned above, the following countermeasures are put forward.

To start with, the teacher could adopt the demonstration and explanation teaching method. For instance, when English teacher introduce the stick figure skill, he or she can draw the picture in the blackboard and emphasize the things students should pay attention to simultaneously. In this way, students can not only learn the theoretical knowledge of the teaching skill without feeling bored, but also grasp the practical application of it with deep impression. Compared with the pure infusion of knowledge, it's both reasonable and effective. Besides, after teachers' demonstration, there should be some time left for students to practice by themselves, and they can give full play with their innovation based on imitation to finish the assignments.
Next, when having English microteaching, it's better to conform the following teaching procedures, which have been already mentioned in chapter two. (1) checking the assignments assigned last class. (2) introducing the teaching content through presentation, inquiring or question discussion. (3) the teacher explains the training form, method and steps. (4) the student prepares lesson and practices it respectively. (5) students have drill in group manner. (6) students are distributed into groups to have microteaching in micro room or laboratory. (7) watching the teaching video and evaluating it from the teacher and students. (8) giving marks and feedback according to the video and recording the results. (9) assigning the training assignments.

Last but not least, English teachers ought to enrich and enlive their teaching through transforming their specific implementation way of teaching activities. For example, teachers should take students' feeling and thoughts into account, especially those introvert and unsocial students. Instead of forcing them to enter into the activity, the teacher can have them actively participate in it by attracting their attention and activate their interests. When questioning students, it's preferable to take the guiding-discovery method rather than directly tell the answers.

\section{Connecting the Individual Skill with the Integrated Skills}

In microteaching, it requires to apply the systematic theory, controlling theory to effectively control the teaching skill. Besides, the reductionism requires to decompose the complicated teaching process into individual skill, as all these skills having reaching the standard, proceeding synthetically practicing. As a matter of fact, none of microteaching skill is existing alone, but interdependent. Thus, we should comprehensively and flexibly apply every teaching skill in order to better complete the teaching task.

First and foremost, English teachers should combine and apply multiple teaching skills when prioritizing teaching one skill, shifting from linear training to comprehensive training, assisting students to handle various skills skillfully. Taking the questioning skill for an example, first, the teacher can concentrate on explaining this skill and later have students show their understanding through imitation. Then, the teacher offers a context, requiring students to apply this skill into it when teaching. Meanwhile, the skills learned last class are also counted into this performance appraisal. After it, the rest students should evaluate the lecturer according to his or her integrated performance, during which the lecturer will consciously take other skills into consideration.

Besides, there is a issue that the English teaching skills students learned in a microteaching room are hard to be transferred to a real teaching class. In other words, there is a lack of teaching context. So, it is necessary to provide a real and vivid skill training context. For example, the normal universities can establish cooperative relationship with local primary and secondary schools. After graduating from the normal school, most students choose teaching profession and teach in these schools. The establishment of this contact in advance will not only help them to master teaching skills, but also pave the way for their future job. Therefore, normal 
students can participate in the primary and middle schools under the guidance of teachers. They can learn English teaching skills through observation, acting as role of teacher. Also, it's an alternative way to invite primary and secondary in-serving teachers to come in micro classrooms to have a demonstration lesson. In this circumstance, normal students are like innocent schoolchildren and these different feelings will certainly add a lot of pleasure.

\section{Establishing Reasonable Evaluation Mechanism}

Evaluation feedback is an important part of microteaching, mainly composed of instructor and student's mutual evaluation reviews. Educational Psychology found that teaching evaluation plays an significant role in promoting and improving teaching and learning effects. In order to improve teaching effectiveness, we can take the following measures:

To begin with, evaluation feedback should meet two conditions at the same time, accuracy and timely. Both are indispensable. The former refers to the faithfulness and reliability of the feedback, while the latter means feedback should be finished before next decision, so that it can play the role of adjusting and controlling. Then, teachers should reinforce the positive guiding effect of evaluation feedback, strengthen guidance and foster students awareness of assessment and good psychological quality. Teachers should encourage students to express their views, reveal problems and improve their bold and courage for facing weakness.

Next, teachers should develop specific and scientific evaluation system to determine the evaluation methods to avoid a mere formality. Evaluation criteria should follow the following requirements: (1) the diversification of subject of evaluation. It's preferable to combine the students' selfassessment, other students' assessment and teacher's summary, with particular attention to exert students' initiative. (2) rationalization of contents. The teaching process can be reasonably decomposed to examine the implementation of various skills. (3) operationalized evaluation criteria. Subject of evaluation and scoring weights should be decomposed. Also, it should be noted that the qualitative and quantitative evaluation are better to be combined and students' emotional experience need to be taken into consideration.

Again, the evaluation belief should be reshaped and the principle ought to be established that "practice is the sole criterion for testing truth." Schools should strengthen the permeation of "real resources" in microteaching, build practical evaluation platform. For example, before conducting microteaching teaching, they can allow students to participate in probation activities to fully experience the real classroom situation, or hiring experienced teachers to explain and demonstrate the lesson. Students can use multimedia to see the design and implementation of the teaching skills in a real classroom. Besides, it's a good choice to establish partnerships with local primary and secondary schools, such as the establishment of "Teachers' Professional Development School" testing student learning in real classroom.

\section{E. Increasing the Class Hours and Necessary Equipment}

Teaching skills in learning theory does not generate its own process of learning, which must be based on teaching theory through repeated training to develop. Therefore, the English normal students should be given a certain proportion of time to the ability of microteaching training. The school can take some effective measures to reach these goals, such as offering night classes once a week for practical training for English pedagogical students. As for the lack of equipment, in addition to the unified arrangement of the school, students can take the "simulated micro teaching" to solve the problem of the device, such as taking the advantages of local conditions with the general popular device, like camera, video player and other audio-visual monitor. Though the training manners are crude, according to the basic principles of micro-teaching, students imitate their relevant teaching skills, which can also achieve satisfactory results. Meanwhile, School leaders should attach much importance to set aside a certain amount of funds for the purchase of essential teaching equipment. Besides, the problems can be solved by improving the using efficiency of teaching equipment. For example, guiding students to master the basic theory of microteaching in advance, having a clear purpose of training in mind, ensuring students are familiar with the methods of operation of the device. Last but not least, by the mutual assisting between one school and another, students can be organized to primary and secondary schools to have internship training, where there are maybe good device condition.

\section{CONCLUSION}

Microteaching is an important opportunity for English normal students to quickly master the majority of English teachers' teaching skills, improve teaching ability and constantly reflect on themselves. Meanwhile, it's an effective way to promote their professional development, from which students are able to realize their own shortcomings and deficiencies on their own. This effect of self-understanding is better than the reminding and correction from instructors, with deeper impression and faster speed. Schools should be under the guidance of modern education idea, making full use of the favorable microteaching environment and modern educational technology. As students play the main character, it's a truly effective means to promote normal students' teaching skills and techniques.

From the perspective of English teachers, this article discusses some of the problems listed about microteaching, including the reasons from students, English teachers and schools, summing up the following points: first, the school should give sufficient attention on microteaching, including the development of the material conditions of investment, related policies and systems for micro-teaching to create an ideal, harmonious environment. Second, English teachers should make fully use of available teaching equipment, textbooks, related teaching aids and other resources to truly play the role of microteaching in training of normal students. At the same time, teachers should seize every training opportunity of microteaching, lectures and seminars, constantly improving their own professionalism. Finally, as a 
protagonist of microteaching learning, English normal students, should raise awareness of their own role, cherish every opportunity to train, down to earth and earnestly grasp the theory as well as practical procedures for microteaching, striving to become an excellent and qualified English teacher.

\section{REFERENCES}

[1] Chen $\mathrm{Li}$ hua. The Implementation of Microteaching system to Cultivate Primary and Middle English Teaching Skills [D]. Hu Bei: Hubei University of Technology.2011.5.

[2] Ji Min. Evaluation of Microteaching in English Pre-service Teacher Education-A case study in Central China Normal University [D]. Wu Han: Central China Normal University, 2012.

[3] Ltd.A, Elsevier. Study on Developing "Microteaching Scale" for Student Teachers [J]. Procedia-Social and Behavioral Sciences, 2012 (46).

[4] Tang Jing. "A Survey of Changsha Primary School English Teachers' Professional Development in the Context of Information Communication Technology [D]." Chang Sha: Hunan University, 2014

[5] Wu, Cui. "Study on Pre-service English Teachers' Professional Skills [D]." Gan Nan: GanNan Normal University, 2014.

[6] Wang Qiang. A Course in English Language Teaching [M]. Beijing: Higher Educational Press, 2006. 